\title{
Plant breeding capacity building in Africa
}

To the Editor - Improving food security requires development of farmer-preferred varieties that are more nutritious and adapted to specific agro-ecologies and changing climatic conditions. Challinor et al. ${ }^{1}$ report that the time from initiating breeding for a trait to adoption of the resulting variety is 18 years, broadly agreeing with other findings that an average age of varieties in use in subSaharan Africa (SSA) is 20 years $^{2}$ - too long compared to the time frame in which climate models predict varietal characteristics will need to change.

A number of interventions ${ }^{1}$ are suggested to improve the effectiveness of investment in varietal development, many of which require significant involvement by practical plant breeders with understanding of the seed business. However, the number of such breeders is limited ${ }^{3,4}$. For example, in 30 SSA countries, the average is about 5 breeders per country to cover all crops, agro-ecological zones, and uses ${ }^{2}$. Therefore, many additional plant breeders are needed in order to avert the impact of climate change on food security in SSA.

In addition to degrees from international higher education institutions, in-region training is needed ${ }^{5}$. In-region training has advantages in cost, relevance, retention, and reduced disruption to family and workplace ties. At the MSc level, two projects funded by the Bill \& Melinda Gates Foundation, 'Improved MSc in cultivar development for Africa' (IMCDA), implemented by Alliance for a Green Revolution in Africa, and 'Plant breeding e-learning in Africa' implemented by Iowa State University, USA, involve three pilot universities: Makerere University (Uganda), Kwame-Nkrumah University of Science and Technology (Ghana), and the University of KwaZulu-Natal (South Africa). These collaborative projects focus on core competencies needed by industryready plant breeders, targeting increased rates of genetic gain by using modern tools: genomics, molecular markers, electronic data collection, data management and breeding pipeline optimization. Training activities and e-learning resources emphasize the application of scientific knowledge to decision making in plant breeding. Students experience best practices in a breeding programme embedded in the training and through internships and links with progressive, efficient cultivar-development programs. Thesis projects focus on national or regional food security issues of many priority African crops, concentrating on traits such as tolerance to drought, diseases and insects in addition to high yield. Ninety students are expected to graduate from these programmes in the next three years, but this is low compared to the overall needs of SSA countries ${ }^{5}$.

Therefore, the throughput of IMCDA and other postgraduate training throughout SSA must be increased. To ensure the sustainability of human capacity development efforts, more investment is needed from governments, development partners and private enterprises. Without such investment, the potential benefits of the proposed interventions ${ }^{1}$ will not be realized. To attract and strategically target such investment, there would be great value in involving key stakeholders in SSA to establish a coordinated strategy of capacity development.

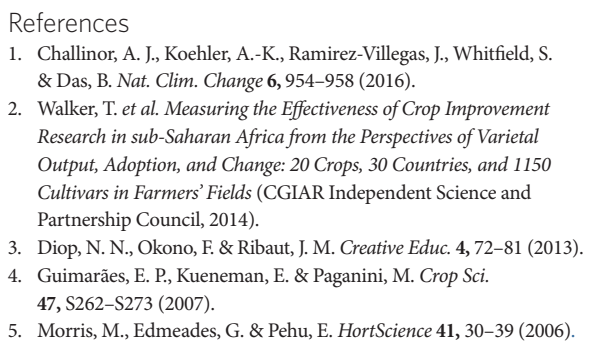

Walter P. Suza ${ }^{1 \star}$, Paul Gibson ${ }^{2}$, Richard Edema ${ }^{2}$, Richard Akromah ${ }^{3}$, Julia Sibiya ${ }^{4}$,

Rufaro Madakadze ${ }^{5}$ and Kendall R. Lamkey ${ }^{6}$

1'lowa State University, Department of

Agronomy, Ames, lowa 50011, USA. ${ }^{2}$ Makerere

University, Department of Agricultural

Production, PO Box 7062, Kampala, Uganda.

${ }^{3}$ Kwame Nkrumah University of Science and

Technology, Department of Crop and Soil

Sciences, University Post Office, Kumasi,

Ghana. ${ }^{4}$ University of KwaZulu-Natal, School of

Agricultural, Earth and Environmental Sciences,

Private Bag X01, Scottsville 3209, South Africa.

${ }^{5}$ Alliance for a Green Revolution in Africa,

PO box 66773, Nairobi, Kenya. ${ }^{6}$ lowa State

University, Department of Agronomy, Ames,

lowa 50011, USA.

*e-mail: wpsuza@iastate.edu

\section{COMMENTARY:}

\section{A science of loss}

\author{
Jon Barnett, Petra Tschakert, Lesley Head and W. Neil Adger
}

\section{Avoiding losses from climate change requires socially engaged research that explains what people value highly, how climate change imperils these phenomena, and strategies for embracing and managing grief.}

ndustrialization, land use change, colonization and mobility have effected a step change in the loss of places, populations, social practices and species over the past five hundred years. Climate change threatens to accelerate losses across social and ecological domains, leading the UNFCCC to establish a mechanism to address these potential losses ${ }^{1}$. However, the concept of loss remains poorly theorized and methods to explain it are few ${ }^{2}$. We outline key elements of a science of loss 